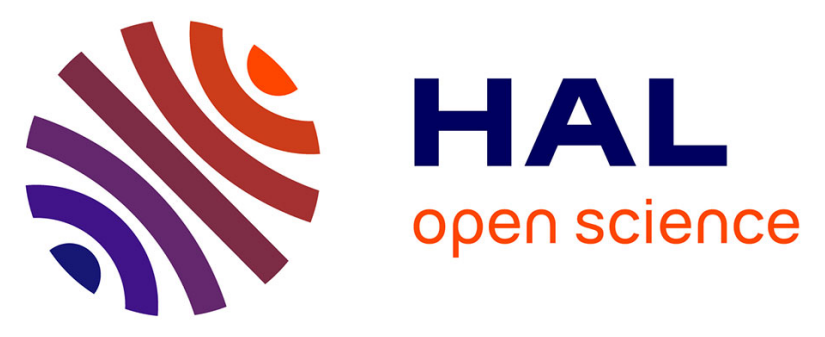

\title{
Adsorption of gastric lipase onto multicomponent model lipid monolayers with phase separation
}

\author{
Claire Bourlieu, Gilles Paboeuf, Sophie Chever, Stephane Pezennec, \\ Jean-François Cavalier, Fanny Guyomarc'H, Amélie Deglaire, Said Bouhallab, \\ Didier Dupont, Frédéric Carrière, et al.
}

\section{To cite this version:}

Claire Bourlieu, Gilles Paboeuf, Sophie Chever, Stephane Pezennec, Jean-François Cavalier, et al.. Adsorption of gastric lipase onto multicomponent model lipid monolayers with phase separation. Colloids and Surfaces B: Biointerfaces, 2016, 143, pp.97-106. 10.1016/j.colsurfb.2016.03.032 . hal-01301356

\section{HAL Id: hal-01301356 \\ https://hal-univ-rennes1.archives-ouvertes.fr/hal-01301356}

Submitted on 13 Jun 2016

HAL is a multi-disciplinary open access archive for the deposit and dissemination of scientific research documents, whether they are published or not. The documents may come from teaching and research institutions in France or abroad, or from public or private research centers.
L'archive ouverte pluridisciplinaire HAL, est destinée au dépôt et à la diffusion de documents scientifiques de niveau recherche, publiés ou non, émanant des établissements d'enseignement et de recherche français ou étrangers, des laboratoires publics ou privés.

\section{(1) (1) $\$$}

Distributed under a Creative Commons Attribution - NonCommercial - NoDerivatives 44.0 


\section{Accepted Manuscript}

Title: Adsorption of gastric lipase onto multicomponent model lipid monolayers with phase separation

Author: Claire Bourlieu Gilles Paboeuf Sophie Chever Stéphane Pezennec Jean-François Cavalier Fanny Guyomarc'h A. Deglaire Saïd Bouhallab Didier Dupont Frédéric Carrière Véronique Vié

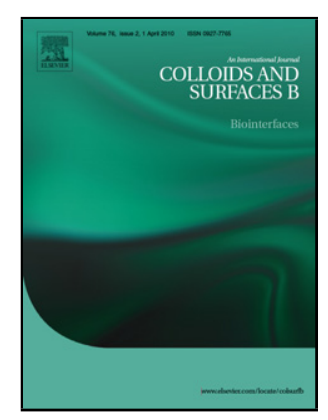

PII:

DOI:

S0927-7765(16)30187-4

Reference: http://dx.doi.org/doi:10.1016/j.colsurfb.2016.03.032

To appear in: $\quad$ Colloids and Surfaces B: Biointerfaces

Received date: $\quad 30-11-2015$

Revised date: $\quad$ 7-3-2016

Accepted date: $\quad$ 10-3-2016

Please cite this article as: Claire Bourlieu, Gilles Paboeuf, Sophie Chever, Stéphane Pezennec, Jean-François Cavalier, Fanny Guyomarc'h, A.Deglaire, Saïd Bouhallab, Didier Dupont, Frédéric Carrigraveere, Véronique Vié, Adsorption of gastric lipase onto multicomponent model lipid monolayers with phase separation, Colloids and Surfaces B: Biointerfaces http://dx.doi.org/10.1016/j.colsurfb.2016.03.032

This is a PDF file of an unedited manuscript that has been accepted for publication. As a service to our customers we are providing this early version of the manuscript. The manuscript will undergo copyediting, typesetting, and review of the resulting proof before it is published in its final form. Please note that during the production process errors may be discovered which could affect the content, and all legal disclaimers that apply to the journal pertain. 
Title: Adsorption of gastric lipase onto multicomponent model lipid monolayers with phase separation

Author names and affiliations: Claire Bourlieu ${ }^{l *}$, Gilles Paboeuf ${ }^{2}$, Sophie Chever ${ }^{l}$, Stéphane Pezennec ${ }^{1}$, Jean-François Cavalier ${ }^{3}, F_{\text {Fanny Guyomarc ' }{ }^{1} \text {, A. Deglaire }}$, Saïd Bouhallab ${ }^{1}$, Didier Dupont ${ }^{1}$, Frédéric Carrière ${ }^{3}$, Véronique Vié ${ }^{2}$

${ }^{1}$ INRA-AGROCAMPUS UMR 1253 STLO, France; ${ }^{2}$ IPR Institute of Physics, Rennes University 1, France $;{ }^{3}$ CNRS, Aix-Marseille University, UMR 7282 EIPL, France ;

* Corresponding author: Dr. Claire Bourlieu, INRA-Agrocampus Rennes, UMR 1253 Science et Technologie du Lait et de l'Oeuf, 65, rue de Saint Brieuc - 35042 Rennes Cedex, telephone : 033499612030 and fax numbers : 033499612393 and E-mail address : claire.bourlieu@rennes.inra.fr.

Present/permanent address: INRA-Agrocampus Rennes, UMR 1253 Science et Technologie du Lait et de l'Oeuf, 65, rue de Saint Brieuc - 35042 Rennes Cedex

Statistical summary of the article:

Total number of words: 5679 words

Total number of tables/figures: 6 
GASTRIC LIPASE ADSORPTION ONTO HETEROGENEOUS LIPID MONOLAYERS: MODEL OF MILK FAT GLOBULE IN THE NEONATAL DIGESTION CONTEXT

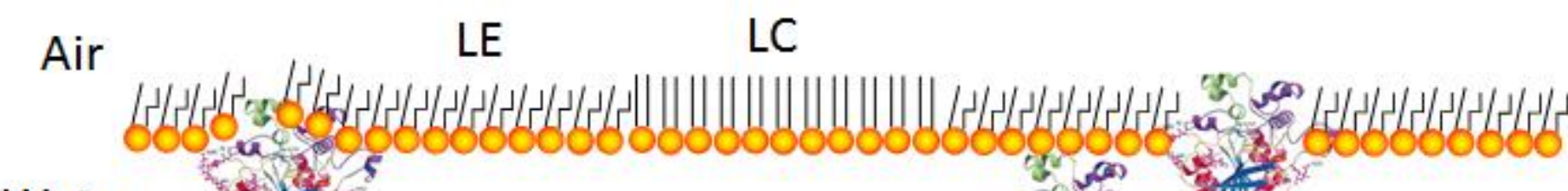
Water

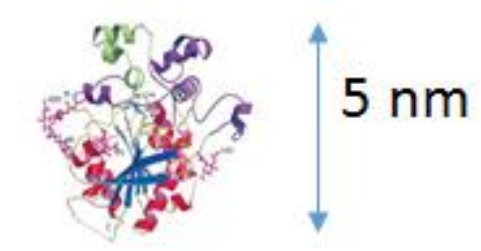

Three main levels of adsorption determined by AFM image analysis

Massive amount of lipase close to interface evidenced by ellipsometry
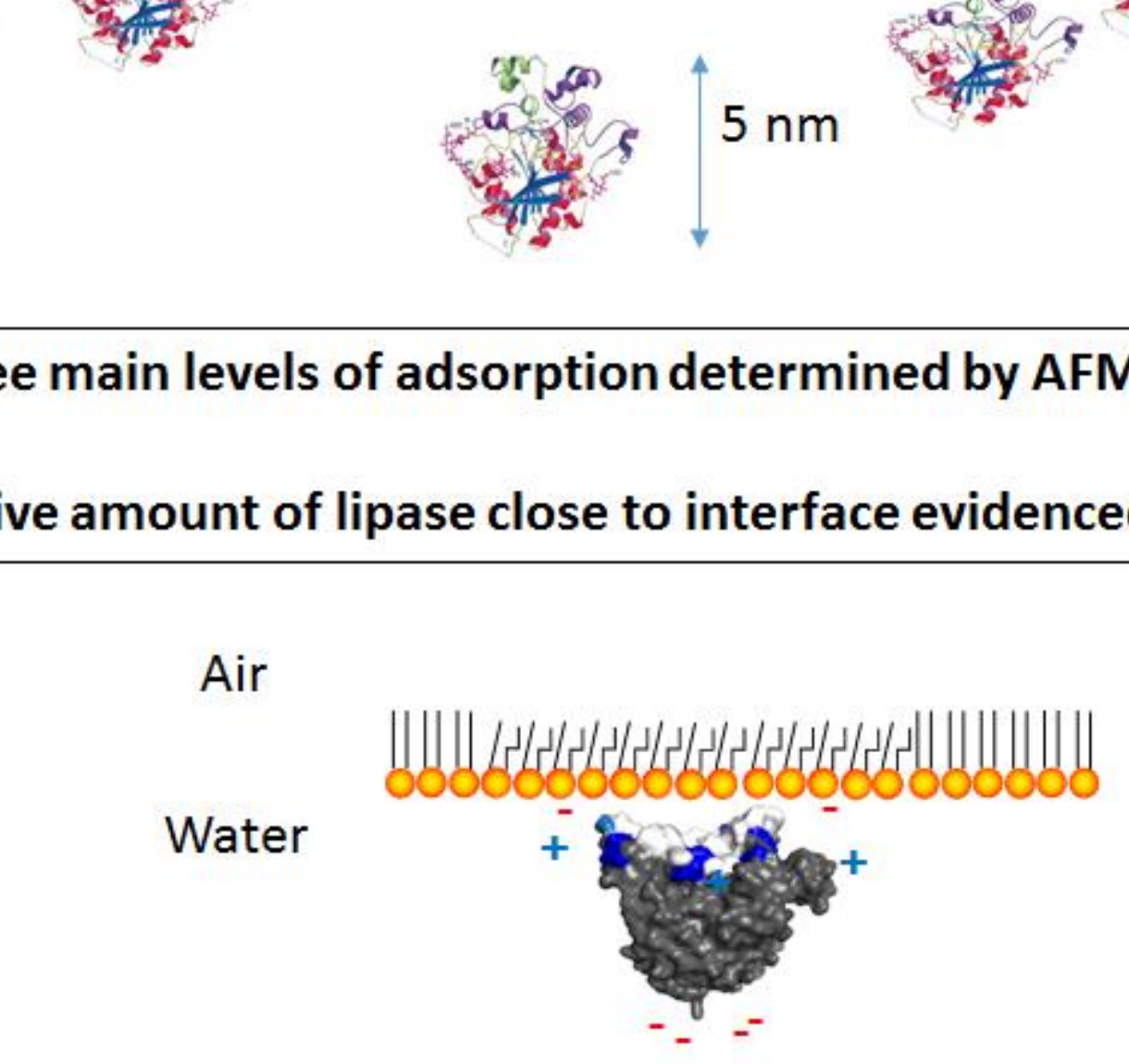

Hydrophobic and electrostatic interactions involved

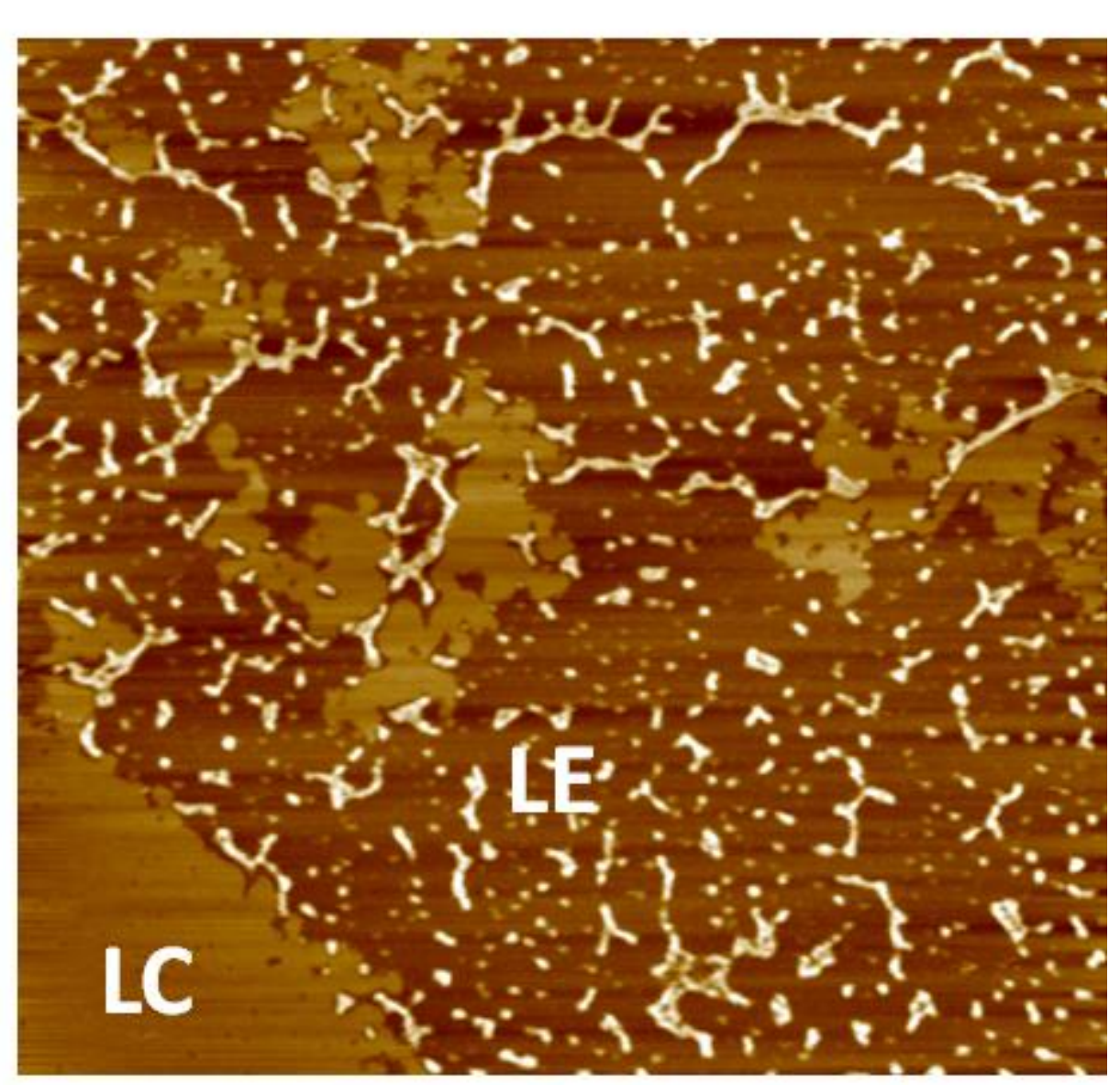

$2.5 \mu \mathrm{m} \times 2.5 \mu \mathrm{m} ; \Delta \mathrm{z}=8 \mathrm{~nm}$

Lipase localisation on LE phase and on LE/LC boundaries 


\section{Graphical abstract}


Highlights

- Ellipsometry evidenced high amount of gastric lipase close to interface

- Gastric lipase adsorption impacts on lipid phase separation

- Gastric lipase partitions towards LE phase in monolayer with phase coexistence

- Gastric lipase adsorbs at variable levels of insertion suggesting variable interaction

- Lipase adsorption is mediated by hydrophobic and electrostatic interactions

ABSTRACT. The enzymatic lipolysis of complex natural lipoproteic assemblies such as milk fat globules is central in neonatal digestion. This process first requires the rapid adsorption of a lipolytic enzyme, gastric lipase, onto the membrane enveloping the triglyceride substrate before the onset of catalytic activity. The interactions governing lipase adsorption onto this complex lipid/water interface are not fully elucidated. This study was designed to unravel the interactions of recombinant dog gastric lipase (rDGL) with model monolayers presenting liquid-liquid phase coexistence and mimicking the outer leaflet of the milk fat globule membrane. Combining biophysical tools (ellipsometry, tensiometry and atomic force microscopy), it was evidenced that rDGL partitions toward liquid expanded phase and at phase boundaries. rDGL gets adsorbed at several levels of insertion suggesting molecular cooperation that may favor insertion and strongly impacts on the lipid phase lateral organization. The addition of phosphatidylserine, negatively charged, reinforced adsorption; hence besides hydrophobic interactions and as further investigated through surface potential modeling, rDGL adsorption is favored by electrostatic interactions.

Abbreviations: AFM, atomic force microscopy; DGL, dog gastric lipase; DOPC, Dioleoylphosphatidylcholine; DPPC, Dipalmitoylphosphatidylcholine; DOPE, Dioleoylphosphatidylethanolamine; DOPS, Dioleoylphosphatidylserine; HGL, human gastric lipase; IRS, interfacial recognition site; GL: gastric lipase; LE, liquid expanded; LC, liquid condensed; MPL: milk polar lipids; PC: Phosphatidylcholine; PE: Phosphatidylethanolamine; PI: phosphatidylinositol; PS: Phosphatidylserine; rDGL: recombinant dog gastric lipase; 
KEYWORDS: Digestive lipase, model lipid monolayer, liquid phase coexistence, milk fat globule, atomic force microscopy. 


\section{INTRODUCTION}

Lipases (EC 3.1.1.3, triacylglycerol hydrolases) are soluble enzymes that cleave the ester bond of water insoluble substrates, triacylglycerols (TG). In humans, TG digestion is initiated in the stomach by human gastric lipase (HGL) [1,2]. Like other lipases, HGL belongs to the $\alpha / \beta$ hydrolase family and possesses a Ser-His-Asp catalytic triad [3]. To catalyze such interfacial reaction, lipases undergoe a conformational change consisting in the opening of an amphiphilic lid that gives access to the active site while it generates a large hydrophobic surface surrounding the catalytic cleft and part of the interfacial recognition site (IRS) [3-6]. HGL has been called "extremophilic" as it is stable and active in the acid environment of the stomach, it is resistant to pepsin hydrolysis and it is not inhibited by the bile salts present in the gastro-intestinal tract [7]. Its optimum activity at acidic $\mathrm{pH}$ (4-5.4) on natural long chain TG emulsions [8] is unique among lipases and is explained by a better adsorption at the lipid/water interface at low $\mathrm{pH}[9,10]$ while, above neutral $\mathrm{pH},[11]$ the enzyme remains in the water phase and is poorly stable [12]. The interfacial characterization of HGL or of close analogues such as dog gastric lipase (DGL, $86 \%$ amino acid sequence identity with human GL) has been investigated using Langmuir films based on lipid homogeneous monolayers. These studies revealed that the interfacial adsorption is $\mathrm{pH}$-dependent and is the rate limiting step of the overall catalytic process [9,10]. Interfacial adsorption of HGL and DGL would be mainly driven by hydrophobic interactions notably via a large apolar ring around the active site cavity which is preserved on a wide range of $\mathrm{pH}$ [10]. Since the adsorption process of HGL is $\mathrm{pH}$-dependent, some electrostatic interactions are probably important but specific amino acids or domains potentially involved in these interactions have not yet been identified.

HGL is not only the first lipase found along the gastro-intestinal tract, it is also produced at high levels in the early life while the production of pancreatic enzymes and bile is still limited [12-14]. In the neonatal context, lipid digestion is crucial for cerebral and global development and growth, and HGL appears as a central enzyme in this process $[12,14]$. HGL is able to initiate the lipolysis of milk fat globules, what is not readily done by pancreatic lipase [15]. HGL can hydrolyze TG embedded in milk fat globules [16-18] and therefore it was hypothesized that HGL can penetrate the milk fat globule 
membrane [19] made of a trilayer of polar lipids and proteins $[17,18,20,21]$. Indeed milk fat globules are based on an apolar core of TG which is enveloped by this complex membrane. The membrane composition reflects its secretory past: the inner membrane is derived from the endoplasmic reticulum whereas the outer bilayer adds on top of the first monolayer when the droplets gets excreted from the mammary secretory cells [22]. Thus, this external bilayer has the typical composition of mammalian cellular membranes. It contains glycerophospholipids (Phosphatidylcholine PC, Phosphatidylethanolamine PE, Phosphatidylinositol PI, Phosphatidylserine PS) but also sphingolipids (mainly Sphingomyelin SM), complex glycolipids, cholesterol and proteins [16]. Such variability of compounds results in a heterogeneous lateral packing of the lipid membrane constituents with a phase separation of liquid ordered (1.o.) microdomains enriched in sphingomyelin and cholesterol [23], and liquid disordered domains (1.d.) enriched in other glycerophospholipids.

Natural membrane that stabilize lipoprotein particles such as the milk fat globule constitute a very good example of complex lipid interface with negative or zwitterionic head-groups and phase separation [22,30]. The distribution of lipases in such an heterogeneous systems presenting phase coexistence $[21,24]$ has only been scarcely characterized $[25,26]$. In homogeneous systems, Balashev and co-workers $[27,28]$ imaged successfully by atomic force microscopy (AFM) lipases on model lipid membranes. Thermomyces (formerly Humicola) Lanuginosus lipase was first visualized in a AFM liquid cell after being trapped in a DPPC monolayer followed by transfer on a DPPC/mica. The lipases appears as protrusion of $2 \mathrm{~nm}$ height over the membrane surface [27]. Then, using hybrid bilayers of DPPC/monooleoylglycerol or DPPC/monopalmitoylglycerol exposed to lipase in liquid cell, the preferential adsorption of Thermomyces lanuginosa lipase or of Candida rugosa lipase onto the edge of nano-scale structural defects was inferred from the growth of these defects following lipase injection $[28,29]$. The initial rate of hydrolysis presented a lag phase for Candida rugosa lipase on DPPC/monopalmitoylglycerol whereas it was not observed for Thermomyces lanuginosa on DPPC/monooleoylglycerol. Authors hypothesized that this difference was linked to the physical state of the substrate (gel phase) which limited enzyme adsorption.

Up to now, the distribution of HGL or of a close mammalian gastric analogue in heterogeneous lipid system has never been studied. Nor the main protein-lipid interactions which drive the enzyme 
partition in the lipid membrane. In the present work, we aimed at elucidating these two points using recombinant DGL as a model of HGL and tensiometry coupled to ellipsometry followed by AFM. Milk fat globule membrane complexity was approached using monolayers of both natural polar lipid extracts of milk fat globule, and binary/ternary/quaternary mixture of purified glycerophospholipids presenting liquid-liquid immiscibility at $20 \mathrm{mN} \cdot \mathrm{m}^{-1}$ and at $20^{\circ} \mathrm{C}$. All experiments were conducted at $20^{\circ} \mathrm{C}$ but in systems presenting similar liquid phase coexistence as observed at $37^{\circ} \mathrm{C}$ in the milk fat globule membrane.

\section{MATERIALS AND METHODS}

\subsection{Lipids}

A bovine buttermilk powder was supplied by LACTALIS (Retiers, France). Milk polar lipid raw fraction (MPL) was purified from this powder by Folch extraction [30] followed by further acetonic purification. Since MPL still contained large amounts of neutral lipids (31.4 \% TG, $69.4 \%$ polar lipids; relative polar lipids composition $\left(\% \mathrm{~mol}^{\mathrm{mol}}{ }^{-1}\right)$ : $\mathrm{PC}=37.0, \mathrm{SM}=33.3, \mathrm{PE}=21, \mathrm{PI}=6.1, \mathrm{PS}=4.1$; sterols $7.6 \pm 3.4 \mathrm{mg} \cdot \mathrm{g}^{-1}$ total fat), MPL was further purified $(<1 \% \mathrm{TG}, 99 \%$ polar lipids, no sterol detected) by preparative thin layer chromatography $\left(\mathrm{MPL}_{\mathrm{TLC}}\right)$. The polar lipid classes and total fatty acids of these two extracts were characterized by HPLC and GC (see supplementary data Figure S1) following methodologies previously published [31].

Blends of glycerophospholipids (Dioleoylphosphatidylcholine DOPC, Dipalmitoylphosphatidylcholine DPP, Dioleoylphosphatidylethanolamine DOPE; Dioleoylphosphatidylserine DOPS; all > 99\% purity; Avanti Polar lipids, Alabaster, Alabama) were tailored to mimic the milk fat globule membrane complexity. Milk fat globule membrane physical behavior was modeled using a simple binary DOPC/DPPC mixture $\left(50: 50 \mathrm{~mol} . \mathrm{mol}^{-1}\right)$ presenting liquid expanded/liquid condensed (LE/LC) phase coexistence and zwitterionic head-groups (PC). Ternary and quaternary mixtures of glycerophospholipids were also prepared (see Table 1 for relative molar composition) to take into account the presence of anionic phospholipids (phosphatidylserine - PS, phosphatidylinositol - PI, $\sim 10 \%$ of total polar lipids) and phosphatidylethanolamine (PE, $20 \%$ total 
polar lipids) in milk membrane. The anionic phospholipids may modify the electrostatic interactions between lipase and interface. While PE modifies lipid head groups packing and may modulate lipase insertion.

\subsection{Enzyme}

Recombinant dog gastric lipase (rDGL) was produced by Meristem Therapeutics (Clermont-Ferrand, France) in transgenic maize and purified as described previously [32]. rDGL stock solution was prepared at a concentration of $1.1 \mathrm{mg} \mathrm{mL}^{-1}$ in $10 \mathrm{mM}$ MES (2-(N-morpholino)ethanesulfonic acid) (pH 6.0) containing $150 \mathrm{mM} \mathrm{NaCl}$ and was further diluted in sodium acetate buffer $(10 \mathrm{mM})$ at $\mathrm{pH} 5$ $\left(100 \mathrm{mM} \mathrm{NaCl}, 20 \mathrm{mM} \mathrm{CaCl}_{2}\right.$ ) prior to monolayer experiments as described previously [9].

\subsection{Ellipsometry and surface tension measurements at the air/water interface}

Experiments were performed using circular Teflon trough (volume $8 \mathrm{~mL}$, surface area $27 \mathrm{~cm}^{2}$ ). Ellipsometric and tensiometric blank measurements were performed during half an hour on ultrapure water (Nanopure-UV) and then on $10 \mathrm{mM}$ sodium acetate buffer (pH 5) containing $100 \mathrm{mM} \mathrm{NaCl}$ and $20 \mathrm{mM} \mathrm{CaCl}$. For the lipid-free interface experiments, the buffer was removed and replaced by a rDGL solution freshly prepared at different concentrations in the range of 5 to $120 \mathrm{nM}$.

The surface pressure $(\pi)$ and the ellipsometric angle $(\Delta)$ were recorded simultaneously. The surface pressure was measured according the Wilhelmy-plate method using a filter paper connected to a microelectronic feedback system for surface pressure measurements (Nima Technology, England) [33]. Values of $\pi$ were recorded every $4 \mathrm{~s}$ with a precision of $\pm 0.2 \mathrm{mN} \cdot \mathrm{m}^{-1}$. Ellipsometric measurements were carried out with a home-made automated ellipsometer in a "null ellipsometer" configuration [34]. The laser beam probed a surface of $1 \mathrm{~mm}^{2}$ and a depth in the order of $1 \mu \mathrm{m}$ and gives insight on the amount of molecules at the interface. Values of $\Delta$ were recorded every $4 \mathrm{~s}$ with a precision of $\pm 0.5^{\circ}$.

Values presented in the various graphs are representative of experiments performed in triplicate.

\subsection{DGL adsorption rate in lipid monolayers at air/water interface}


The monolayer was formed by spreading a few microliters of the lipid solution $\left(10 \mathrm{mg} \cdot \mathrm{mL}^{-1}\right.$ in chloroform) over the clean air/buffer interface of the $8 \mathrm{~mL}$ cylindrical trough using a high precision Hamilton microsyringe until an initial surface pressure of $20 \pm 0.5 \mathrm{mN} \cdot \mathrm{m}^{-1}$ was reached. rDGL was further injected into the sub-phase of the trough at a $40 \mathrm{nM}$ final concentration. The surface pressure increase due to the protein insertion into the lipid monolayer was continuously recorded until the equilibrium surface pressure was reached.

The experimental data (i.e. surface pressure increase, $\Delta \pi$, were next fitted to the Langmuir adsorption equation adapted to surface pressure measurements (eq (1)):

$$
\pi(t)=\pi_{i}+\Delta \pi_{\max } \cdot \theta \cdot[1-\exp (-\sigma \cdot t)](1)
$$

where $\pi(t)$ is the surface pressure measured as a function of time; $\pi$ is the initial surface pressure; $\Delta \pi_{\max }$ is the maximum variation of surface pressure reached upon lipase binding; $\theta$ $=k_{a \cdot} C_{E 0} /\left(k_{a} \cdot C_{E 0}+k_{d}\right)$ is the fraction of the total free adsorption (binding) sites coverage; $\sigma=\left(k_{a} \cdot C_{E 0}+k_{d}\right)$ and $C_{E 0}\left(m o l . L^{-1}\right)$ is the lipase concentration in the subphase of the trough (for a detailed discussion about this mathematical approach see [9]).

Curve-fitting the experimental data points to eq (1), using KaleidaGraph 4.1 software from Synergy Software, allowed to determine the adsorption $\left(k_{\mathrm{a}}, \mathrm{M}^{-1} \cdot \mathrm{s}^{-1}\right)$ and desorption $\left(k_{\mathrm{d}}, \mathrm{s}^{-1}\right)$ rate constants from the slope and y-intercept, respectively, of the linear plot of $\sigma$ versus $\mathrm{C}_{E 0}$. The adsorption equilibrium coefficient, $K_{\text {Ads }}\left(\mathrm{M}^{-1}\right)$, which represents the binding affinity between the protein and the lipid film, was obtained from the ratio of the measured rate constants $\left(K_{\mathrm{Ads}}=k_{\mathrm{a}} / k_{\mathrm{d}}\right)$.

\subsection{Atomic force microscopy}

For AFM imaging, the film was transferred onto a freshly-cleaved mica plate by the LangmuirBlodgett method. The transfer was done at a constant surface pressure and at a very low speed $(0.5$ $\mathrm{mm} \mathrm{min}^{-1}$ ). The mica plate was further observed with an AFM (Molecular Imaging, Pico+, Plus, Scientec, France). Imaging was carried out in contact mode in air $\left(20^{\circ} \mathrm{C}\right)$ with standard silicon cantilevers (spring constant of 0.06 or $0.12 \mathrm{~N} . \mathrm{m}^{-1}, \mathrm{SNL}$, Bruker, France), and at a scan rate of $1 \mathrm{~Hz}$. 
The force was minimized during all scans. To verify the integrity of samples after the different scans and zooms, the same zone was imaged at the end of the analysis. The scanner size is $100 \times 100 \mu \mathrm{m}^{2}$. Presented images are representative of at least duplicated experiments. The images were processed (flattened using $2^{\text {nd }}$ level of polynomial processing implemented on Picoscan 5.3 software (Molecular Imaging Corporation, San Diego, USA). The processed images were analyzed by the open-source platform FIJI [35]. The differences of height between LC and LE phases ( $\left.\Delta_{\mathrm{LC}-\mathrm{LE}}\right)$ were assessed by random measurements $\left(\mathrm{N}=20\right.$ on $8 \times 8 \mu \mathrm{m}^{2}$ image $)$ on cross-sections of the image using Picoscan 5.3. The phase separation and distribution of the lipase in the image were further investigated using FIJI [35] as detailed in Supplementary Data (Figure S2). Comparison of this approach with LangmuirSchaefer transfer followed by liquid cell imaging was also made in preliminary test (see Supplementary Data Figure S4). However, local desorptions of the bilayer were difficult to avoid as already reported [28] and induced local holes or reorganisation. Thus we decided in the present study to study lipase adsorption in heterogeneous monolayer using mainly Langmuir-Blodgett films.

DGL electrostatic surface potential modeling. Electrostatic surface potentials for DGL in open conformation (X-ray 3D structure; pdb id: 1K8Q) and closed conformation (DGL 3D model built from the closed X-ray 3D structure of HGL (pdb id: 1HLG) and DGL-HGL sequence alignment) were built using freely available PDB2PQR web service [36,37]. pKa calculations were concomitantly performed with PropKa [38] to assign protonation states of each protein at $\mathrm{pH} 5$ (i.e. the working $\mathrm{pH}$ of monolayer experiments). The electrostatic potential data thus generated, were further visualized using the PyMOL-APBS Tools2 plugin [39]. Field forces were visualized using the same input data using VDM.EXE. 


\section{RESULTS}

\subsection{Adsorption of rDGL at the air/water interface}

On the tested range of concentrations ( 5 to $120 \mathrm{nM}$, i.e. 0.24 to $5.81 \mathrm{mg} . \mathrm{L}^{-1}$ of lipase), ellipsometric angle increased from $0^{\circ}$ up to $17^{\circ}$ (Figure S3 A). The value of $17^{\circ}$ was already reached at $60 \mathrm{nM}$, afterwhich a plateau was observed. At low concentration (0 to $10 \mathrm{nM})$, surface pressure $(\pi)$ remained equal to zero but it increased sharply beyond $10 \mathrm{nM}$ reaching $17 \mathrm{mN} \cdot \mathrm{m}^{-1}$ at $40 \mathrm{nM} ; \pi$ values then levelled off reaching $20 \mathrm{mN} \cdot \mathrm{m}^{-1}$ at $120 \mathrm{nM}$.

The observed plateau at concentrations larger than 40-60 nM indicated that the rDGL was forming a protein monolayer. The protein concentration used in the next experiments, was then fixed at $40 \mathrm{nM}$, i.e., just below the rDGL surface saturation.

\subsection{Adsorption of rDGL onto monolayers of milk polar lipid extracts and model glycerophospholipid mixtures spread at the air/water interface}

Monolayers of milk polar lipid raw fraction (MPL), enriched MPL (MPL $\mathrm{TLC}_{\text {) }}$ and five mixtures of glycerophospholipids (Table 1) were selected for studying rDGL adsorption by ellipsometry and tensiometry. All mixtures presented liquid-liquid phase immiscibility and lateral heterogeneity. Extraction of parameters $\left(\Delta \pi, \Delta \pi_{\max }, \delta \Delta\right)$ from the experimental curves is explained below and is illustrated in Figure 1 on MPL. Parameters are summarized in Table 1. Following lipase injection, the variation of both ellipsometric angle and surface pressure was correlated with an influx of lipase triggering reorganization in the monolayer followed by the relaxation of the film. Maximal increase in surface pressure indicating protein insertion at the lipid interface was recorded as $\Delta \pi_{\max }$ (Figure 1). This short-term increase ranged between $2.4 \mathrm{mN} \cdot \mathrm{m}^{-1}$ on MPL and $6.1 \mathrm{mN} \cdot \mathrm{m}^{-1}$ on MPL TLC (Table 1). The difference between the initial (time 0 ) and final (5 hours) surface pressures of the system, called $\Delta \pi$, gives an indication on the long-term stability of the monolayer with adsorbed rDGL (Figure 1). This parameter was very close to $\Delta \pi_{\max }$ on the two MPL extracts (Table 1) in line with the good stability of these systems following rDGL adsorption. A very high increase in the ellipsometric angle between injection and final time (i.e., $\delta \Delta$ ) was observed on the two natural MPL monolayers. 
$\Delta \pi_{\max }$ values obtained on model glycerophospholipid monolayers were highly dependent on the lipid blend composition (Table 1). With neutral DOPC/DPPC (50:50) monolayer, $\Delta \pi_{\max }$ was low with a value of $0.3 \pm 0.6 \mathrm{mN} \cdot \mathrm{m}^{-1}$. The addition of a phospholipid with smaller polar head (DOPC/DPPC/DOPE 40:40:20), thus limiting steric hindrance, triggered an increase of $\Delta \pi_{\max }$ up to $2.2 \pm 1.4 \mathrm{mN} \cdot \mathrm{m}^{-1}$. An even higher increase of $\Delta \pi_{\max }$ (up to $5.4 \pm 3.4 \mathrm{mN} \cdot \mathrm{m}^{-1}$ ) was obtained after adding negatively charged phospholipids (PS, DOPC/DPPC/DOPS 45:45:10). Increasing further the amount of PS in the model system, from 10 to $20 \mathrm{~mol} \%$, did not intensify this trend $\left(\Delta \pi_{\max }=0.8 \pm 0.3 \mathrm{mN} \cdot \mathrm{m}^{-1}\right)$. Similarly, the more complex lipid mixture of DOPC/DPPC/DOPE/DOPS displayed a low $\Delta \pi_{\max }$ value of $0.6 \pm 0.3 \mathrm{mN} \cdot \mathrm{m}^{-1}$.

For all the model glycerophospholipid monolayers, rDGL adsorption induced a very important increase of ellipsometric angle $(\delta \Delta)$ which ranged between $4.8 \pm 0.5^{\circ}$ and $8.2 \pm 0.8^{\circ}$ on DOPC/DPPC and DOPC/DPPC/DOPS (45:45:10), respectively (Table 1). In addition to these changes in the equilibrium values of $\delta \Delta$ measured after 5 hours, the short term variations of the ellipsometric angle $(\Delta)$ during the adsorption kinetics of rDGL was also affected by the lipid composition (Figure 1B).

\subsection{Kinetics of adsorption of rDGL onto selected monolayers}

To further characterize the differences in rDGL adsorption kinetics onto lipid monolayers, a new series of adsorption experiments $\left(\pi_{i}=20 \mathrm{mN} \cdot \mathrm{m}^{-1}\right)$ were performed in a round Langmuir Teflon ${ }^{\mathrm{TM}}$ trough for rDGL concentrations ranging between 20 and $120 \mathrm{nM}$. The resulting adsorption equilibrium coefficients, $K_{\text {Ads, }}$ which indicate the binding affinity between the protein and the lipid film, were two orders of magnitude higher on DOPC/DPPC/DOPS (45:45:10) MPL than on DOPC/DPPC monolayers. With $k_{\mathrm{d}}\left(\mathrm{s}^{-1}\right), k_{\mathrm{a}}\left(\mathrm{M}^{-1} . \mathrm{s}^{-1}\right)$ and $\mathrm{K}_{\text {Ads }}\left(\mathrm{M}^{-1}\right)$ of respectively: $5.15 \times 10^{-5}, 3.48 \times 10^{4}, 6.76 \times 10^{8}$ on DOPC/DPPC/DOPS $(45: 45: 10) ; 2.94 \times 10^{-4}, 3.32 \times 10^{4}, 1.13 \times 10^{8}$ on MPL; $1.24 \times 10^{-3}, 0.39 \times 10^{4}$, $3.12 \times 10^{6}$ on DOPC/DPPC.

\subsection{Visualization by AFM of lipase insertion into monolayers}

AFM observations of the Langmuir-Blodgett lipid films in the absence or after injection of rDGL in the subphase, were conducted to investigate the distribution of rDGL at the nanoscale level (Figure 2). In all systems without rDGL, Langmuir-Blodgett films displayed typical phase separation with LC (lighter zones) and LE (background) domains of variable shapes and size depending on the lipid 
composition (Figure 2A). These domains were very irregular on the three model systems (DOPC/DPPC, DOPC/DPPC/DOPE and DOPC/DPPC/DOPS) but more circular on natural MPL extracts. Difference of height between LC and LE domains ranged from 1.1 and $1.8 \mathrm{~nm}$ (Table 2), with the lowest $\Delta_{\mathrm{LC}-\mathrm{LE}}$ obtained in the presence of DOPE.

The addition of rDGL clearly modified the lipid films whatever the system. In all systems except the MPL $_{T L C}$, rDGL injection enhanced the circularity of large LC domain. Besides, rDGL injection triggered the appearance of smaller domains, sometimes aligned and linked by small "grains" of variable heights. These small LC domains covered an average area of $0.05-0.08 \mu \mathrm{m}^{2}$ whereas the mean area before the addition of rDGL was larger (0.51-0.85 $\mu \mathrm{m}^{2}$, Table 2). Nevertheless, the difference of height between LC and LE did not vary upon rDGL addition. On MPL ${ }_{\mathrm{TLC}}$ Langmuir-Blodgett films, injection of rDGL also resulted in more spherical LC domain and in the appearance of interconnected 'grains' in the LE phase but these grains were more numerous, and at a much more regular height than in the other systems (Figure $2 \mathrm{~A}$ ).

From these observations, we set the hypothesis that the 'grains' appearing in the systems after rDGL addition, were rDGL molecules either adsorbed onto or inserted into the lipid film. It is worth noticing that these grains appeared in the LE phase mainly or at LE-LC phase boundaries. These 'grains' were clearly displayed on the cross-sections profile of the AFM images (Figure 2A, left panel), where sharp peaks appeared in the presence of rDGL only whatever the systems. The peaks presented variable heights, but were subdivided in three categories depending on their height levels and frequency (Figure 3). Numerous peaks $\left(h_{3}\right)$ could be visualized either between 0 and $2 \mathrm{~nm}$, i.e. between the levels of LE and LC domains (small peaks), or at intermediate heights $\left(\mathrm{h}_{2}\right)$ ranging between 3 and $4 \mathrm{~nm}$ i.e. just above the LC height. Lastly, less frequent but sharp peaks with a height $\left(\mathrm{h}_{1}\right)>5 \mathrm{~nm}$ were also detected. Image analysis allowed quantifying the average surface covered by $h_{1}$ and $h_{2}$ peaks in most systems (Table 2). The highest peaks $\left(\mathrm{h}_{1}\right)$ covered $8-11 \%$ of the surface and presented an area of 0.001-0.002 $\mu \mathrm{m}^{2}$. The intermediate peaks $\left(\mathrm{h}_{2}\right)$ covered between 1-3\% of the surface and developed an average area of $4.2-5.2 \times 10^{-4} \mu \mathrm{m}^{2}$. The smallest peaks $\left(\mathrm{h}_{3}\right)$ could not be differentiated from LC small domains, which covered 15 to $18 \%$ of the surface and developed larger average areas of 0.05 to 0.08 
$\mu \mathrm{m}^{2}$ (see Figure S2 in Supplementary Data and Table 2). Only $h_{2}$ and $h_{3}$ heights were present in the

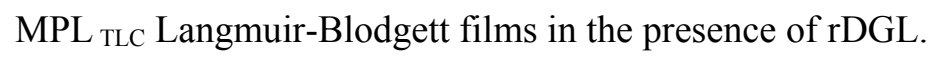

$8 \times 8 \mu \mathrm{m}^{2}$ images (Figure $2 \mathrm{~A}$ ) were adequate to visualize all the objects in our systems: lipid phase separation and lipase distribution. More resolute images of $2.5 \times 2.5 \mu \mathrm{m}^{2}$ are also displayed in Figure 2B on which the smallest protrusions $24-30 \times 10^{-6} \mu \mathrm{m}^{2}$ correspond to the molecular area of rDGL $\left(\sim 19.6 \times 10^{-6} \mu \mathrm{m}^{2}\right)$. In addition, the distribution of rDGL was also comforted by AFM imaging of Langmuir-Schaefer films in liquid cell as displayed in supplementary data (Figure S4).

\section{DISCUSSION}

\section{1. rDGL is characterized by a high interfacial affinity (air/water or lipid/water) despite limited insertion}

The binding capacity of proteins at air/water and lipid/water interfaces is generally monitored as the increase in surface pressure $\left(\Delta \pi_{\max }\right)$ which is connected both to the fraction of protein inserted at the interface and to variations of the interfacial film molecular packing. This parameter on its own does not describe the degree of insertion of the protein within the interface. Additional information can be obtained by coupling surface pressure and ellipsometric angle measurements [40].

In the experiments of rDGL adsorption at the air/liquid interface, very high values $\left(15-17^{\circ}\right)$ of ellipsometric angle $\Delta$ were obtained for rDGL (from 1.9 to $5.8 \mathrm{mg} \cdot \mathrm{L}^{-1}$ ). Such high values suggested that an important amount of protein was present in the first micrometer below the air/liquid interface [40-42]. In comparison, maximum ellipsometric angle values of $6^{\circ}$ or $11^{\circ}$ were reported respectively for apolipoprotein $1(23 \mathrm{Kda}, 53 \mathrm{nM})$ [43] or for globular proteins having molecular masses close to that of rDGL such as ovalbumin $(45 \mathrm{kDa})$, forming a monolayer. This was observed at a higher concentration $\left(\sim 10\right.$ g.L $\left.\mathrm{L}^{-1}\right)$ than in our system [44]. The same authors also evidenced extreme value of ellipsometric angle of $21^{\circ}$ for lysozyme $\left(14 \mathrm{kDa}, 10 \mathrm{~g} \cdot \mathrm{L}^{-1}\right)$, a smaller globular protein that however forms multilayers [44].

Regarding rDGL, the linear evolution of surface pressure versus ellipsometric angle following the lipase injection into the subphase (Figure S3B): it is typical of protein monolayer formation [45].The stability of both $\pi$ and $\Delta$ values after $100-120 \mathrm{nM}$ indicates the saturation of the interface by rDGL 
molecules forming a stable interfacial monolayer of proteins. Similar findings were reported for rDGL adsorption onto a hydrophobic solid surface at $\mathrm{pH}$ 5. Using a quartz crystal microbalance, it was shown that rDGL formed a single monolayer covering the entire surface (surface occupancy $99.1 \%$; $419 \pm 25 \mathrm{ng} \cdot \mathrm{cm}^{-2} ; 505 \times 10^{10}$ molecule. $\mathrm{cm}^{-2}$ ) [10]. Therefore, rDGL adsorption is clearly distinct from that of globular proteins forming multilayers and characterized by an increase in ellipsometric angle at constant surface pressure.

The maximum surface pressure $\left(20 \mathrm{mN} \cdot \mathrm{m}^{-1}\right)$ reached at $120 \mathrm{nM} \mathrm{rDGL}$, is in the range of pressure reported for other amphiphilic globular proteins $\left(26 \mathrm{mN} \cdot \mathrm{m}^{-1}\right.$ for ovalbumin, $20 \mathrm{mN} \cdot \mathrm{m}^{-1}$ for lysozyme [40]) or for exchangeable apolipoproteins (22.5 to $26.5 \mathrm{mN} . \mathrm{m}^{-1}$ for ApoA-I and ApoC-III) [45]. Thus, while a large amount of rDGL molecules are at the air/liquid interface, the lateral molecular cohesiveness is relatively low.

The adsorption of rDGL onto model glycerophospholipid monolayers (initial $\pi=20 \mathrm{mN} \cdot \mathrm{m}^{-1}$ ) triggered an increase in surface pressure ranging from 0.3 to $6.1 \mathrm{mN} \cdot \mathrm{m}^{-1}$. This increase was coherent with data reported at same initial surface pressure for rDGL adsorption onto dilauroylphosphatidylcholine monolayers (pH 5.0, $\Delta \pi \sim 8 \mathrm{mN} \cdot \mathrm{m}^{-1}$, critical pressure for insertion $\pi_{c}$ of $21.5 \mathrm{mN} . \mathrm{m}^{-1}$ ) [9] and for HGL adsorption onto egg PC monolayers (pH 5.4, $\Delta \pi \sim 3 \mathrm{mN} \cdot \mathrm{m}^{-1}$, critical pressure for insertion $\pi_{c}$ of around $22 \mathrm{mN} \cdot \mathrm{m}^{-1}$ ) [46]. In our study, rDGL highest binding affinity and insertion were recorded with DOPC/DPPC/DOPS (45:45:10) and MPL (Table 1). The $K_{\text {Ads }}$ values obtained on these later monolayers were close to those determined using a solid hydrophobic surface $\left(K_{\text {Ads }}=1.5 \times 10^{8} \cdot \mathrm{M}^{-1}\right)$ [10], using a pure non-hydrolysable dilauroylphosphatidylcholine monolayer $\left(K_{\mathrm{Ads}}=1.7 \times 10^{8} \cdot \mathrm{M}^{-1}\right)$ [9] or using a mixed dicaprin-orlistat (lipase inhibitor) monolayer $\left(K_{\mathrm{Ads}}=1.22 \times 10^{8} \cdot \mathrm{M}^{-1}\right)$ [47]. Increasing further the DOPS molar fraction (20\%) in the mixed monolayer DOPC/DPPC/DOPS resulted in a lower insertion of rDGL at the interface: there might be an optimum distribution of negative charges present at the interface for rGDL adsorption, or alternatively more addition of DOPS to the monolayer may change the charge repartition in the film and induce protein repulsion. Conversely, the enrichment in polar lipids of MPL (MPL $\left.{ }_{T L C}\right)$ resulted in a higher insertion of rDGL. The mechanisms by which these later changes in lipid composition or the type of interface affect rDGL insertion can hardly be explained at this stage, since these changes concern both the chemistry, the mixture and the 
phase behavior of lipids spread at the interface. Residual triglycerides (TG; around $30 \% \mathrm{w} / \mathrm{w}$ ) in MPL, are potential substrates for rDGL that can release free fatty acids. Free fatty acid incorporated in phospholipid monolayers mediate the adsorption of pancreatic lipase, colipase and carboxylester lipase, probably by concentrating fatty acids laterally in nano-domains surrounding the protein $[48,49]$. This mechanism can not directly be transposed to rDGL for which we observed a lower adsorption in MPL in the presence of putative free fatty acids than in MPL $\mathrm{TLC}_{\text {. }}$

The higher adsorption of rDGL in the natural extracts can be linked to their heterogeneity of acyl chain lengths and the presence of short/medium acyl chains in MPL (see Figure 1 in supplementary data) compared to model blends of glycerophospholipids. This favorable impact of short chains was already postulated by Bénarouche et al. [9] who reported higher critical surface pressure $\pi_{c}$ onto dilauroylphosphatidylcholine (medium C12 acyl chains) monolayer compared to egg PC (longer and unsaturated C16-C18 acyl chains) monolayer. Generally speaking, the tensiometry and ellipsometry data compiled for rDGL at the air/water or lipid/water interface in the present work suggest that a large amount of the lipase molecules adheres onto the interface rather than fully penetrates into the interface which is in agreement with conclusions on lipase adsorption reported by Chu and coworkers [25] or Piéroni and co-workers [50].

\section{2. rDGL partitions towards the LE phase in model membrane with phases coexistence and impacts}

\section{on phase separation}

Limited studies are available about the lateral distribution of lipases in model membrane with phase coexistence despite the obvious biological interest of such systems. More studies have been conducted by AFM in homogeneous supported monolayers or bilayers, using phospholipases [51-53] and lipases [27-29,54]. These studies generally indicated that phospholipases and lipases adsorb preferentially at the edge of defects, where less tight molecular spacing and the increase of curvature favor the adsorption of amphiphiles. In the present study, AFM imaging revealed that rDGL preferentially adsorbs onto the LE phase presenting less tight molecular packing and at the boundaries of LC domains of heterogeneous systems. A similar and selective adsorption of colipase and pancreatic lipase onto mixed DPPC-bile salts LE regions and not in the DPPC-LC domains was previously reported [25]. The close packing of the hydrophilic lipid headgroups of DPPC in LC domains 
prevented lipase adsorption by steric hindrance. In this system mimicking intestinal digestion, bile salts adsorbed onto DPPC interface, spaced out the DPPC molecules and disordered their packing. As the adsorption of bile salts progressed, some large LC domains were fractionated into smaller domains which resulted in more phase edges where lipase adsorption was favored.

The insertion of rDGL in mixed lipid monolayer also induced the appearance of small, sometimes interconnected, nano-domains of extended or irregular shapes on one side, and, on the other side, also increase the circularity of large microdomains. Variations in the size and shape of domains is regulated by various mechanisms such as hydrophobic mismatch between lipid species, charge repulsions, protein-lipid interactions, line tension effects at domains boundaries [55]... It is generally recognized that the distribution of domain sizes is highly dependent on the balance between: 1) line tension which favors an increase in the size of domains to limit domain boundary and entropy, and 2) electrostatic repulsions which tend to limit domains merging. If the variations of domain sizes triggered by lipase adsorption are based on changes in line tension, one can speculate that lipase adsorption modifies the balance between the opposing forces of line tension and dipole densities, and that this change is not homogeneous in the monolayer. Indeed the evolution of large domains towards more circular domains is consistent with higher line tension at these boundaries. Conversely, the appearance of small and irregularly shaped domains in other regions of the monolayers indicates domains with a pattern governed by dipolar or electrostatic interactions between molecules. Since all saturated lipids are not in LC at the initial surface pressure of $20 \mathrm{mN} \cdot \mathrm{m}^{-1}$, we can hypothesize that lipase recruits and condenses some lipids containing saturated chains. The appearance of domain alignments after lipase adsorption was previously observed by epifluorescence and at a higher scale when Rhizopus delemar lipase was injected below a didecanoylglycerol/eicosanoic acid (90:10) lipid film [26]. These authors postulated that the free fatty acids released by the lipase in this system may contribute to lipid reorganization and to the appearance of alignments after lipase adsorption. In the present study with rDGL, these domain alignments were observed in MPL system containing hydrolysable TG but also in other systems with no lipase substrate, thus indicating that the contribution of dipole density was observed even in the absence of hydrolysis products such as fatty acids. 
Alignments of lipase molecules were also observed at LC domains boundaries in our study. An analogous distribution was reported for lipidated peptides adsorbed onto a ternary DOPC/DPPC/Cholesterol (1:2:1) lipid membrane [56]. The lipidated peptides were expelled from the lipid system due to hydrophobic mismatch. The authors raised the hypothesis that such protein sublocalization and accumulation at domain interface favor protein interaction and is a vehicle for protein association.

\subsection{Adsorption of rDGL in lipid monolayers is mediated by hydrophobic and electrostatic interactions}

As for other lipases, the rDGL 3D structure is characterized by the presence of a lid that controls the access to the active site. Under the open conformation of the lid, the 3D structure of rDGL shows a large hydrophobic surface surrounding the entrance of the active site [6]. It was checked by in silico titration that the large apolar ring surrounding the active-site cavity is preserved whatever the $\mathrm{pH}$ and that the protein was positively charged below $\mathrm{pH} 5$ [10]. Although hydrophobic interactions appear to be an important driving force for rDGL binding onto various interfaces $[9,10]$, the strong $\mathrm{pH}$ dependence of rDGL adsorption suggests that electrostatic interactions are also involved. Since the pH-dependent adsorption of rDGL was first observed on a solid hydrophobic surface containing no charge, it was hypothesized that intramolecular electrostatic interactions governing the stabilization of lid opening (salt bridge) were involved and favored at low $\mathrm{pH}[10]$. Nevertheless, it is shown here that addition of a small amount of negative charges using phosphatidylserine (10\%) enhances rDGL insertion at the interface.

rDGL surface potential modeling at pH 5 (Figure 4) indicates positive charges on the edges of the apolar ring surrounding the lipase active site, while a patch of negative charges is located opposite to the entrance of the active site. This specific distribution of charges, in addition to hydrophobic interactions, may facilitate the orientation of the lipase close to a negatively charged lipid interface. This distribution should result in an attraction of the positively charged ring and a repulsion of the part opposite to the active site (Figure 4 A). A similar distribution of charges is also present in HGL (Data not shown). In DGL, the positive charges are mainly displayed by Lys4, Lys186, Lys194, Lys204, Lys210, His215, H216, Arg229, Lys280, Lys 283, as well as by the N-terminal amine group of Leu1. 
These basic residues are all found within four peptide stretches potentially involved in the interfacial recognition site (IRS) of rDGL [4]: Leu1-Lys4 (DGL N-terminus), Lys186-Pro214 (Lid region), His215-Phe246, Gln277-Lys283, these two latter regions being partly uncovered upon lid opening (Figure S5). Other residues from these peptide stretches are mainly hydrophobic and form the apolar ring $\left(2,209 \AA^{2}\right)$ representing $57 \%$ of the total accessible surface of the IRS $\left(3,860 \AA^{2}\right)$. Basic are the second most represented amino acids ( $919 \AA^{2} ; 24 \%$ of IRS accessible surface).

\subsection{Model of rDGL distribution in heterogeneous monolayer presenting LE/LC phase coexistence}

Several depths of penetration of rDGL were evidenced by cross-sections and image analysis which back up the hypothesis of variable insertion of the lipase depending on the local lateral packing of the lipids. The resulting model of the distribution of rDGL in heterogeneous monolayer is presented in Figure 3. This model describes three main depths of penetration and levels of interaction for the lipase in heterogeneous monolayer. Light had already been shed on the variable depth of penetration of rDGL onto dilauroylphosphatidylcholine films depending on film initial surface pressure [9]. Here we describe two additional levels observed in heterogeneous monolayers. The first additional level $\left(\mathrm{h}_{1}\right)$ corresponds to lipase molecules adsorbed underneath the monolayer and interacting with polar head only, which is coherent with important ellipsometric angle increase with limited surface pressure change. Intermediate depth of penetration $\left(\mathrm{h}_{2}\right)$ corresponds to an insertion of the lipase on 1-2 nm which could correspond to the active form of the lipase interacting with the monolayer as already suggested by previous authors $[9,27]$. The third additional level $\left(\mathrm{h}_{3}\right)$ may correspond to lipase molecules totally inserted on 3-5 $\mathrm{nm}$ and probably denaturated at the interface. Most lipolytic enzymes, including gastric lipase, are irreversibly denatured and inactivated when they bind a lipid/water interface at high surface tension/low surface pressure [4]. Their activity can be preserved by lowering surface tension with amphiphiles like proteins and bile salts $[57,58]$. The lipase itself can play this role if sufficient amounts of the enzyme are added. Here, the first lipase molecules binding the interface could serve as sacrificing agents contributing to lower surface tension upon their insertion and denaturation. The fact that lipid phase separation mediates amphiphile proteins association was already hypothesized by several authors [56,59]. 


\section{CONCLUSIONS}

Using a combination of biophysical tools (ellipsometry, tensiometry, AFM) and model monolayers of polar lipids mimicking the outer leaflet complexity of the milk fat globule, it was evidenced that, rDGL, taken as an example of amphiphile monomeric lipase, exhibited a rapid adsorption onto the LE phase and at boundaries of LC phase at $20 \mathrm{mN} \cdot \mathrm{m}^{-1}$. This adsorption process is mediated via hydrophobic but also electrostatic interactions, is characterized by a massive amount of gastric lipase located close to the substrate as revealed by ellipsometry and results in three main levels of adsorption of the protein. The specific composition of the milk fat globule membrane, containing small amount of negatively charged phospholipids (PS and PI), small to medium chains and LE phase, is favorable for a fast adsorption of GL onto its substrate in neonates. This may constitute a key advantage to catalyze the subsequent lipolysis reaction. The massive amount of lipase molecules located close to the lipid interface may further favor a rapid hydrolysis of the milk fat during neonatal digestion.

Acknowledgments. INRA CEPIA department is acknowledged for funding of the research enclosed in the manuscript 


\section{References}

[1] F. Carrière, J. A. Barrowman, R. Verger, R. Laugier, Gastroenter., 105 (1993) 876.

[2] C. Roman, F. Carrière, P. Villeneuve, M. Pina, V. Millet, U. Simeoni, J. Sarles, Ped.Res., 61 (2007) 83.

[3] S. Canaan, A. Roussel, R. Verger, C. Cambillau, Biochim.Biophys.Acta, 1441 (1999) 197.

[4] A. Aloulou, J. A. Rodriguez, S. Fernandez, D. Van Oosterhout, F. Carrière, Biochim.Biophys.Acta, 1761 (2006) 995.

[5] M. E. Lowe, J.Lipid Res., 43 (2002) 2007.

[6] A. Roussel, N. Miled, L. Berti-Dupuis, M. Rivière, S. Spinelli, P. Berna, V. Gruber, R. Verger, C. Cambillau, J.Biol.Chem. 277 (2002) 2266.

[7] A. Aloulou, F. Carrière, Cell.Mol.Life Sci., 65 (2008) 851.

[8] F. Carrière, H. Moreau, V. Raphel, et al., European J.Biochem., 202 (1991) 75.

[9] A. Bénarouche, V. Point, G. Parsiegla, F. Carrière, J. F. Cavalier, Coll.Surf.B., 111 (2013) 306.

[10] H. Chahinian, T. Snabe, C. Attias, P. Fojan, S. B. Petersen, F. Carrière, Biochem., 45 (2006) 993.

[11] E. Ville, F. Carrière, C. Renou, R. Laugier, Digestion, 65 (2002) 73.

[12] C. Bourlieu, O. Ménard, K. Bouzerzour, G. Mandalari, A. Macierzanka, A. R. Mackie, D. Dupont, Crit.Rev.Food Sci.Nutr., 54 (2014) 1427.

[13] S. Lindquist, O. Hernell, Curr.Opin.Clin.Nutr.Metab.Care, 13 (2010) 314.

[14] J. Sarles, H. Moreau, R. Verger, Acta Paediatr., 81 (1992) 511.

[15] S. Bernback, L. Blackberg, O. Hernell, J.Clin.Invest., 85 (1990) 1221.

[16] B. Y. Fong, C. S. Norris, A. K. H. MacGibbon, Int. Dairy J., 17 (2007) 275.

[17] S. Gallier, D. Gragson, R. Jimenez-Flores, D. Everett, J.Agric.Food Chem., 58 (2010) 4250.

[18] C. Lopez, M. N. Madec, R. Jimenez-Flores, Food Chem., 120 (2010) 22.

[19] P. Walstra, (1995) Advanced Dairy Chemistry Volume 2, Fox, P. F., editor. Chapman and Hall, London.

[20] J. M. Evers, R. G. Haverkamp, S. E. Holroyd, G. B. Jameson, D. D. S. Mackenzie, O. J. McCarthy, Int.Dairy J., 18 (2008) 1081.

[21] S. Gallier, D. Gragson, R. Jimenez-Flores, D. W. Everett, J.Agric.Food Chem., 58 (2010) 12275.

[22] T. Keenan, J.Mammary Gland.Biol.Neoplasia, 6 (2001) 365. 
[23] F. Guyomarc'h, S. Zou, M. Chen, P. E. Milhiet, C. Godefroy, V. Vié, C. Lopez, Langmuir, 30 (2014) 6516.

[24] R. Waninge, T. Nylander, M. Paulsson, B. Bergenstahl, Chem.Phy.Lipids, 125 (2003) 59.

[25] B. S. Chu, A. P. Gunning, G. T. Rich, M. J. Ridout, R. M. Faulks, M. S. J. Wickham, V. J. Morris, P. J. Wilde, Langmuir, 26 (2010) 9782.

[26] G. H. Peters, U. Dahmen-Levison, K. de Meijere, G. Brezesinski, S. Toxvaerd, H. Mahwald, A. Svendsen, P. K. J. Kinnunen, Langmuir, 16 (2000) 2779.

[27] K. Balashev, L.K. Nielsen, T.H. Callisen, A. Svedsen, T. Børnholm, Probe Microscopy, 2 (2001) 177.

[28] K. Balashev, T.R. Jensen, K. Kjaer, T. Børnholm, Biochimie, 83 (2001) 387.

[29] N. Prim, L. Iversen, P. Diaz, T. Bjornholm, Coll.Surf.B., 52 (2006) 138.

[30] J. Folch, M. Lees, G. H. Sloane-Stanley, J.Biol.Chem., 226 (1957) 509.

[31] C. Bourlieu, F. Rousseau, M.-N. Madec, V. Briard-Bion, B. Bouhallab, C. Lopez, Food Res.Int., 40 (2009) 533

[32] A. Roussel, S. Canaan, M. P. Egloff, M. Rivière, L. Dupuis, R. Verger, C. Cambillau, J.Biol.Chem., 274 (1999) 16995.

[33] I. Langmuir, The constitution and fundamentals properties of solids and liquids. II Liquids. 39 (1917) 1848.

[34] B. Berge, A. Renault, Europhysics Letters, 21 (1993) 773.

[35] J. Schindelin, I. rganda-Carreras, E. Frise, V. Kaynig, M. Longair, T. Pietzsch, S. Preibisch, C. Rueden, S. Saalfeld, B. Schmid, J. Y. Tinevez, D. J. White, V. Hartenstein, K. Eliceiri, P. Tomancak, A. Cardona, Nat.Meth., 9 (2012) 676.

[36] T. J. Dolinsky, J. E. Nielsen, J. A. McCammon, N. A. Baker, Nucleic Acids Res., 32 (2004) W665.

[37] T. J. Dolinsky, P. Czodrowski, H. Li, J. E. Nielsen, J. H. Jensen, G. Klebe, N. A. Baker, Nucleic Acids Res., 35 (2007) W522.

[38] H. Li, A. D. Robertson, J. H. Jensen, Proteins, 61 (2005) 704.

[39] N. A. Baker, D. Sept, S. Joseph, M. J. Holst, J. A. McCammon, Proc.Natl.Acad.Sci.U.S.A., 98 (2001) 10037.

[40] J. A. De Feijter, J. Benjamins, F. A. Veer, Biopolymers, 17 (1978) 1759.

[41] J. N. Herron, W. Mueller, M. Paudler, H. Riegler, H. Ringsdorf, P. A. Suci, Langmuir, 8 (1992) 1413.

[42] H. Motschmann, R. Reiter, R. Lawall, G. Duda, M. Stamm, G. Wegner, W. Knoll, Langmuir, 7 (1991) 2743. 
[43] L. Chièze, V. M. Bolanos-Garcia, M. Pinot, B. Desbat, A. Renault, S. Beaufils, V. Vié, J.Mol.Biol. $410(2011) 60$.

[44] S. Pezennec, F. Gauthier, C. Alonso, F. Graner, T. Croguennec, G. Brulé, A. Renault, Food Hydrocolloids, 14 (2000) 463.

[45] V. M. Bolanos-Garcia, A. Renault, S. Beaufils, Biophys.J., 94 (2008) 1735.

[46] L. La Fournière, M. G. Ivanova, J. P. Blond, F. Carrière, R. Verger, Coll.Surf.B., 2 (1994) 585.

[47] A. Bénarouche, V. Point, F. Carrière, J. F. Cavalier, Biochimie, 101 (2014) 221.

[48] I. P. Sugar, N. K. Mizuno, M. M. Momsen, H. L. Brockman, Biophys.J., 81 (2001) 3387.

[49] S. G. Bhat, H. L. Brockman, Biochem., 21 (1982) 1547.

[50] G. Piéroni, Y. Gargouri, L. Sarda, R. Verger, Adv.Coll.Interface Sci., 32 (1990) 341.

[51] L. K. Nielsen, J. Risbo, T. H. Callisen, T. Bjornholm, Biochim.Biophys.Acta., 1420 (1999) 266.

[52] F. Noll, C. May, H. Kindl, Biophys.Chem., 86 (2000) 29.

[53] H. Wu, L. Yu, Y. Tong, A. Ge, S. Yau, M. Osawa, S. Ye, Biochim.Biophys.Acta., 1828 (2013) 642.

[54] K. Balashev, N. John DiNardo, T. H. Callisen, A. Svendsen, T. Bjornholm, Biochim.Biophys.Acta., 1768 (2007) 90.

[55] A. J. Garcia-Saez, S. Chiantia, P. Schwille, J.Biol.Chem., 282 (2007) 33537.

[56] K. Weise, G. Triola, S. Janosch, H. Waldmann, R. Winter, Biochim.Biophys.Acta., 1798 (2010) 1409.

[57] Y. Gargouri, G. Pieroni, P. A. Lowe, L. Sarda, R. Verger, Eur.J.Biochem., 156 (1986) 305.

[58] T. Tsujita, H. Okuda, J.Lipid Res., 31 (1990) 831.

[59] L. J. Johnston, Langmuir, 23 (2007) 5886. 


\section{Figure legends}

Figure 1. Evolution of Surface pressure (circles; $\pi, \mathrm{mN} . \mathrm{m}^{-1}$ ) and/or Ellipsometric angle (triangles; $\Delta$, $\left.{ }^{\circ}\right)$ during the experiments of rDGL adsorption (40 $\mathrm{nM}$ final sub-phase concentration) onto lipid monolayers preformed at an initial surface pressure of $20 \mathrm{mN} \cdot \mathrm{m}^{-1}$. A) Kinetic example showing the different experimental parameters used $\left(\Delta \pi_{\max }, \Delta \pi\right.$ and $\left.\delta \Delta\right)$ on MPL monolayer. B) Variations of Ellipsometric angle $\left(\Delta,{ }^{\circ}\right)$ during rDGL adsorption onto DOPC/DPPC/DOPE (40:40:20, grey line) and DOPC/DPPC/DOPS (45:45:10, black line) monolayers. Curves obtained for three independent assays to illustrate the initial variability of ellipsometric signal.

Figure 2. Monolayers imaged by AFM in the presence or in the absence of rDGL. A) $8 \times 8 \mu \mathrm{m}^{2}$ images and corresponding cross-section. Left panel, AFM images of Langmuir-Blodgett films (initial surface pressure of $20 \mathrm{mN} \cdot \mathrm{m}^{-1}$ ) before (- rDGL) or after injection of rDGL (40 nM final sub-phase concentration, + rDGL). Right panel, representative cross-section of each type of sample used to determine the average differences of height between LC and LE phases which are summarized in Table 2. B) Example of more resolute $2.5 \times 2.5 \mu \mathrm{m}^{2}$ AFM images. Insets show examples of height profile of protrusions on the $2.5 \times 2.5 \mu \mathrm{m}^{2}$ images which correspond to the lipase. The films were transferred on mica 40 min after lipid deposition (without lipase) and 2 hours after injection of the lipase in the systems.

Figure 3. Model of rDGL distribution in heterogeneous monolayer presenting LE/LC phase coexistence. Legend: (a) Lipase adsorption at the edges of large LC domains results in increase in line tension and sharper edges reducing the entropy of the system, (b) Lipase adsorption onto the LE phase and at boundaries of LC domains in heterogeneous monolayer results in an increase in electrostatic interactions between molecules, in small nanodomains alignments; $h_{1}$ ) Lipase adsorbed underneath interacting with polar head only, rapid adsorption evidenced by ellipsometry; $\mathrm{h}_{2}$ ) Insertion of lipase on 1-2 $\mathrm{nm}$ depth, such insertion is coherent with the penetration depth already reported [9], i.e. $1.15 \mathrm{~nm}$ at $20 \mathrm{mN}$ for the lipase active form; $\mathrm{h}_{3}$ ) Lipase totally inserted on $3-5 \mathrm{~nm}$, probably denaturated at the 
interface and contributing to lower surface tension. Possibly favoring insertion of active lipase molecules $\left(\mathrm{h}_{2}\right)$ by spacing lipid molecules in LE and serving as sacrificing agents.

Figure 4. 3D structure of rDGL in its open conformation. Panels A and B show side views of rDGL oriented perpendicular to the interface with the interfacial recognition site (IRS) on the top. Panel A shows surface representation model with hydrophobic and basic residues are shown in white and blue color, respectively, while other residues are shown in dark grey. Panel B shows ribbon representation of rDGL 3D structure with secondary structure elements. In panel B Electrostatic surface potential of open rDGL 3D structure was calculated at $\mathrm{pH}$ 5. The electrostatic surface potentials were displayed color-coded onto a van der Waals surface using the PyMOL Molecular Graphics System (version 1.3, Schrödinger, LLC). Red and blue colors represent net negative and positive charges, while white color represents overall neutral positions, respectively. Field forces were visualized in panel B using VDM.EXE. 
A)

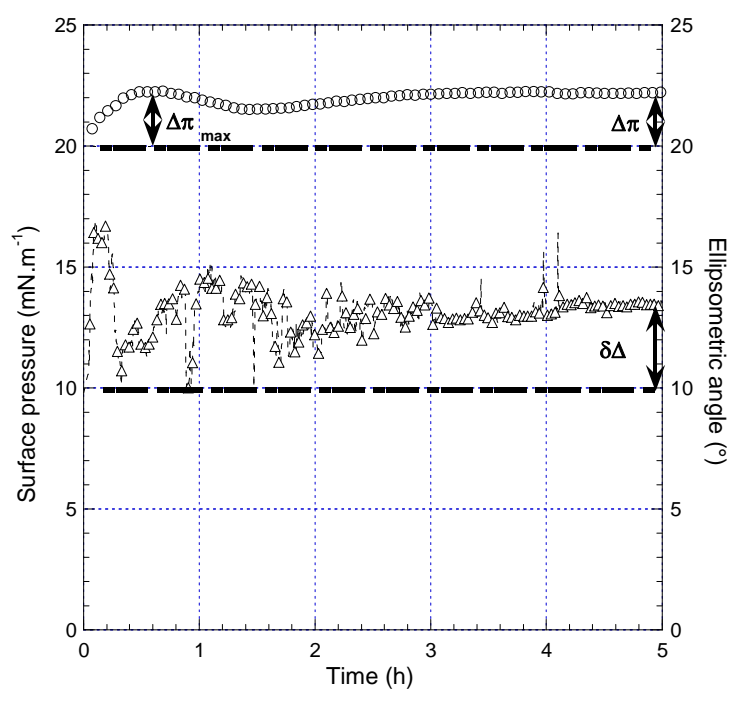

B)

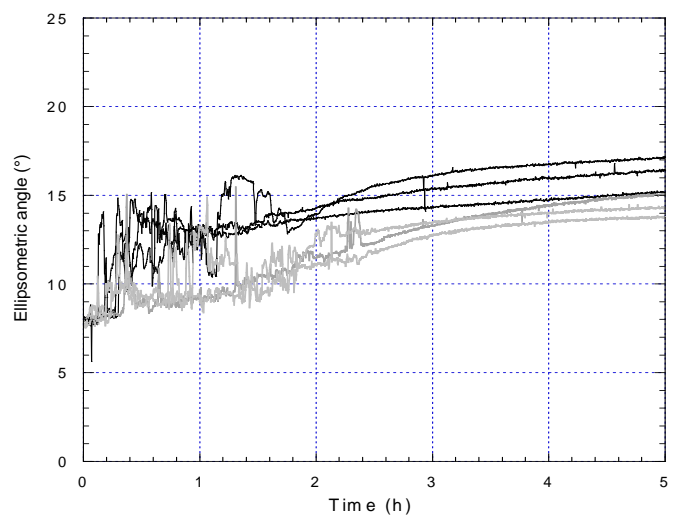

Figure 1.

26 


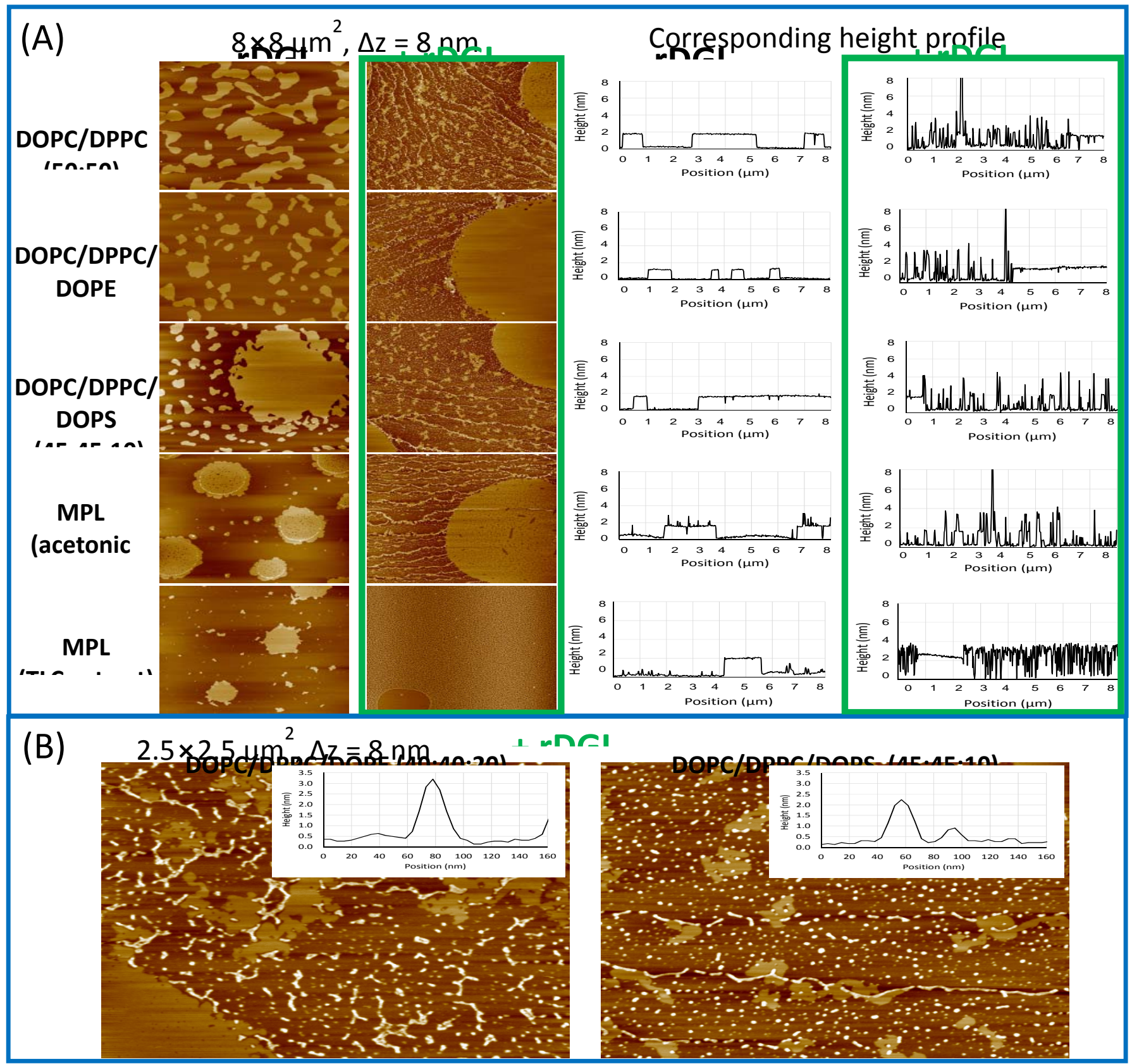




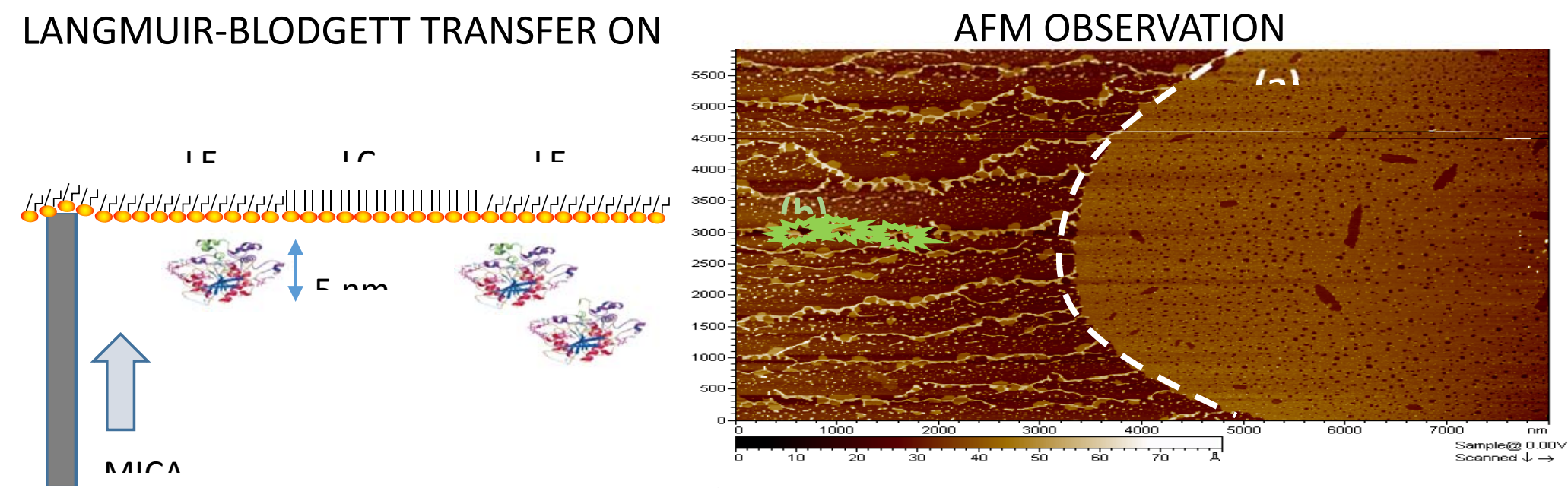

Figure 3.

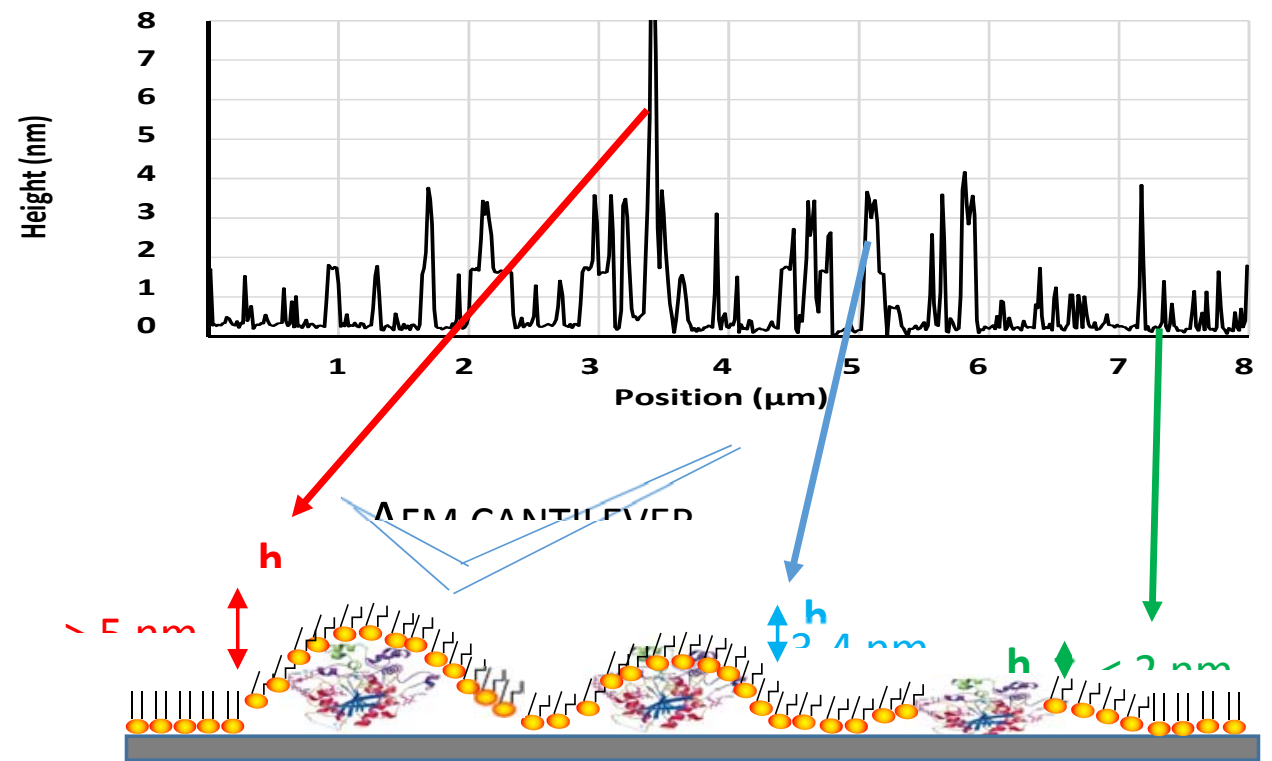



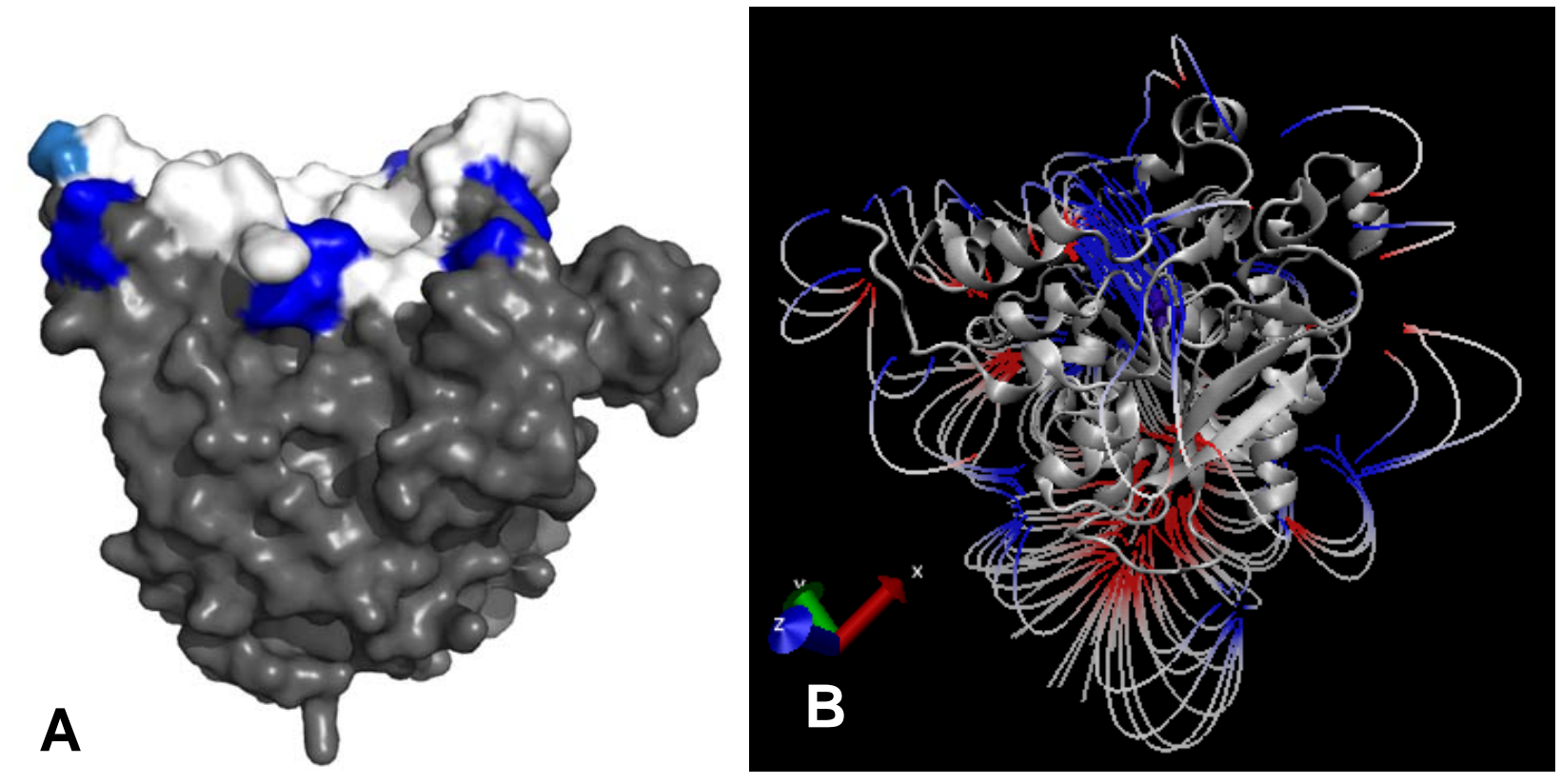

Figure 4 . 
Tables.

Table 1. Summary of variation of ellipsometric angle $(\delta \Delta)$ and surface pressure $\left(\Delta \pi, \Delta \pi_{\max }\right)$ following rDGL injection below monolayer of model lipid mixtures mimicking the milk fat globule membranes and monolayers of polar lipids extracted from milk fat globules over 5 hours.

\begin{tabular}{|c|c|c|c|}
\hline Monolayer composition & $\begin{array}{c}\Delta \pi_{\max } \\
\left(\mathrm{mN} \cdot \mathrm{m}^{-1}\right)\end{array}$ & $\begin{array}{c}\Delta \pi \\
\left(\mathrm{mN} \cdot \mathrm{m}^{-1}\right)\end{array}$ & $\begin{array}{l}\delta \Delta \\
\left({ }^{\circ}\right)\end{array}$ \\
\hline MPL & $2.4 \pm 0.4$ & $2.3 \pm 0.2$ & $3.1 \pm 1.4$ \\
\hline MPL TLC $_{\text {Th }}$ & $6.1 \pm 0.2$ & $7.1 \pm 1.1$ & $18.3 \pm 6.5$ \\
\hline 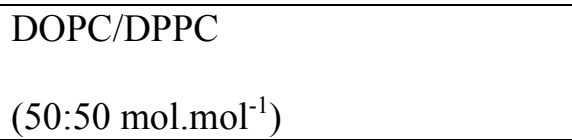 & $0.3 \pm 0.6$ & $-2.2 \pm 1.2$ & $4.8 \pm 0.5$ \\
\hline 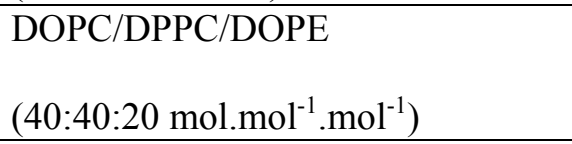 & $2.2 \pm 1.4$ & $-0.1 \pm 1.5$ & $6.9 \pm 0.8$ \\
\hline $\begin{array}{l}\text { DOPC/DPPC/DOPS } \\
\left(45: 45: 10 \mathrm{~mol} \cdot \mathrm{mol}^{-1} \cdot \mathrm{mol}^{-1}\right)\end{array}$ & $5.4 \pm 3.4$ & $4.0 \pm 3.1$ & $8.2 \pm 0.8$ \\
\hline $\begin{array}{l}\text { DOPC/DPPC/DOPS } \\
\left(40: 40: 20 \mathrm{~mol} \cdot \mathrm{mol}^{-1} \cdot \mathrm{mol}^{-1}\right)\end{array}$ & $0.8 \pm 0.3$ & $-1.3 \pm 0.1$ & $5.5 \pm 0.5$ \\
\hline $\begin{array}{l}\text { DOPC/DPPC/DOPE/DOPS } \\
\left(35: 35: 20: 10 \mathrm{~mol}^{\mathrm{mol}}{ }^{-1} \cdot \mathrm{mol}^{-1} \cdot \mathrm{mol}^{-1}\right)\end{array}$ & $0.6 \pm 0.3$ & $-3.3 \pm 0.8$ & $5.2 \pm 0.5$ \\
\hline
\end{tabular}


\pm stands for calculated standard deviation on at least three measurements; for $\Delta$ since the system/instrumentation error is \pm 0.5 , calculated $\mathrm{SD} \leq 0.5$ were minored by this instrumentation error. 
Table 2. Summary of the various parameters obtained from AFM images analysis using FIJI with injected in the subphase.

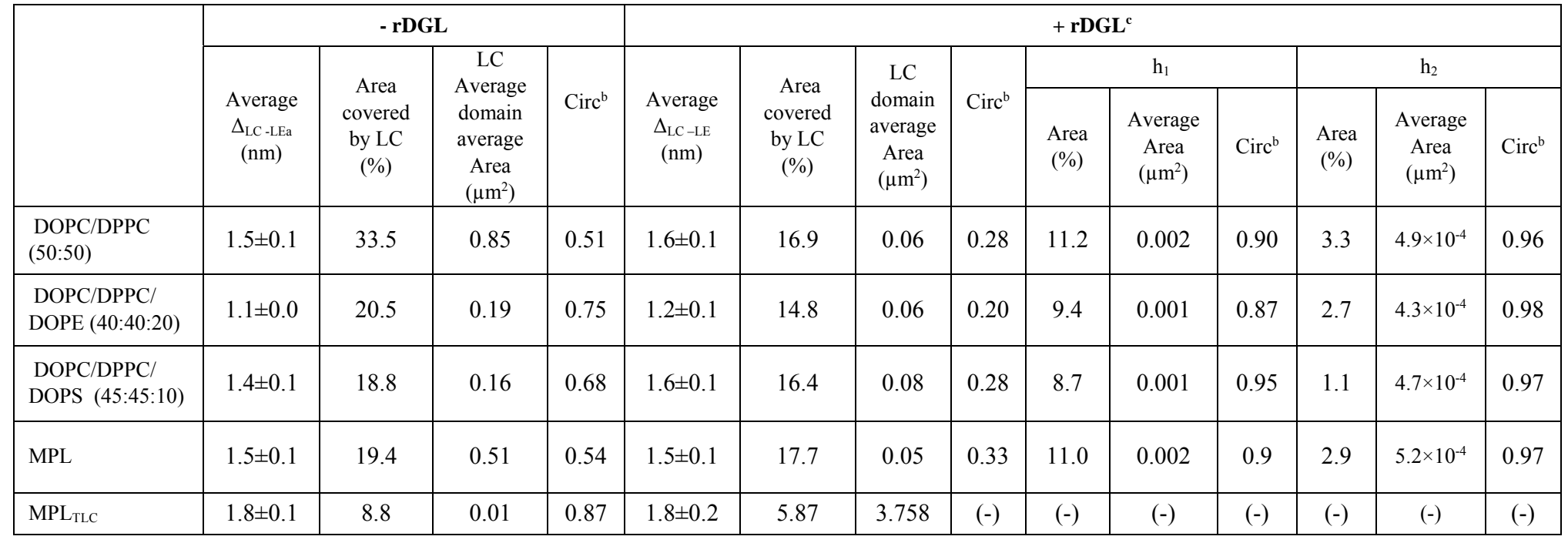

${ }^{\mathrm{a}}$ Values were estimated by 20 random measurements on one $8 * 8 \mu \mathrm{m}$ image. \pm values stands for calculated standard deviation on the 20 measurements. ${ }^{\mathrm{b}}$ Circularity $(\mathrm{Circ})=4 \pi$ (particle_area/perimeter $\left.{ }^{2}\right)$. A value of 1.0 indicates a perfect circle.

${ }^{\mathrm{C}}$ In the presence of rDGL, very large microdomains were excluded from the portion of the analyzed image to get rid of the bias they would trigger on image analysis. 